http://dx.doi.org/10.12795/PH.1990.v05.i01.21

\title{
Bohemia y Licantropía: intertextualidad de diferencias en un cuento de Bioy Casares
}

Carmen Espejo Cala

La narrativa de Adolfo Bioy Casares supone en las letras argentinas la consolidación de un cierto hacer literario donde triunfan la ironía, la ligereza, un fino humor que reviste las cuestiones más trascendentes. Con antecedentes como Macedonio Fernández y en compañía inseparable de Borges, sus novelas y cuentos afirman la posibilidad de la literatura como juego, discurso lúdico, artificial.

Entre otros recursos de su técnica la crítica viene destacando con insistencia el reconocimiento de la intertextualidad según la definiera Julia Kristeva. $\mathrm{M}^{\mathrm{a}}$ Isabel Tamargo identifica la fórmula principal del procedimiento intertextual en Bioy Casares: la impune utilización de un lenguaje del «sentido común» que deviene inmediatamente «sospechoso» aplicado a los conocidos universos fantásticos del autor. Una ficticia «ilusión de profundidad de la literatura realista» encubre un texto autorreferente, concebido como producto de sí mismo1. Así, es frecuente la articulación de lugares comunes o frases hechas -procedimiento que Severo Sarduy catalogó como barroco-, el empleo de nombres propios históricos o de ficciones célebres y finalmente las alusiones metaliterarias que a veces conducen al lector a la cabal interpretación del texto y otras lo despistan irremediablemente. Habla Tamargo entonces de «intertextualidad de diferencias», ya que, más que recrear la tradición, Bioy Casares parece proponerse una revisión en clave irónica del legado cultural.

Un relato de fines de los años sesenta, «Confidencias de un lobo», supone un perfecto ejemplo de tales afirmaciones. Recogido en la colección El gran serafín,

${ }^{1} \mathrm{M}^{\mathrm{a}}$ Isabel Tamargo, La narrativa de Bioy Casares (Madrid: Nova, 1983), p. 11. 
publicada por primera vez en Buenos Aires en 1967, desarrolla las desventuras de cuatro turistas argentinos -Tarantino, Sarcone, Escobar y Rivero Puig- que recorren Europa bajo la eficiente organización de una agencia de viajes porteña. El narrador en tercera persona fluctúa entre la omnisciencia y la visión con Rivero Puig, a través de quien asistimos a los desesperados esfuerzos de los amigos por añadir a las escasas emociones del tour la de una conquista galante. El desánimo cundirá entre el grupo cuando también se resistan las jóvenes parisinas, tras infructuosos intentos en Barcelona, Génova, Niza y cada una de las escalas anteriores. Por fin Tarantino, Sarcone y Escobar trabarán relación con una empleada del hotel, y Rivero Puig quedará aislado y aburrido en la gran ciudad, aplicándose un epíteto que se autoimpone con melancólico orgullo: «un lobo solitario ${ }^{2}$. Mientras contempla distraído el escaparate de un taxidermista, se compara al lobo de Siberia disecado, «carnicero, reputado por la soledad y el hambre», y encuentra en él «su más cabal símbolo, su imagen más viva»³.

Pero a los pocos pasos aparece la que será primera presa del astuto cazador, Mimí, una joven parisina moderna e ingenua que compartirá una tarde de amor con el argentino, en un sucio hotel de apariencia poco respetable. Cuando a la mañana siguiente el autobús de la agencia lo conduce a Dinard, centro balneario francés un tanto monótono, en Rivero brotará, junto a la satisfacción y la nostalgia, un asomo de amor por Mimí, pronto postergado ante la posibilidad de un nuevo trofeo: ahora, una esposa adúltera a quien conoce en el hotel. El asedio se desarrolla sin dificultades hasta que la señora revela su verdadera condición cuando pide al desconcertado argentino doscientos francos por anticipado. Más aún, acaba con todo su vanidoso historial erótico al descubrirle casualmente que Mimí -cuya auténtica nacionalidad no es la francesa, sino la alemana- es una prostituta más que tiene la debilidad de simular una tarde de amor y dispensar de sus honorarios al incauto que la confunde con una buena chica.

Las alusiones metaliterarias se dirigen a distintas direcciones e incluyen referencias a otras narraciones de Bioy Casares: el cuento «Encrucijada», que sitúa de nuevo a ciudadanos argentinos en la vieja Europa; el relato «Todas las mujeres son iguales», donde se ironiza con esta propensión del argentino moderno a probar suerte allende sus costas; o el cuento «Un león en el bosque de Palermo», donde un personaje diserta sobre el insospechado poder de los instintos humanos que nos asemeja a fieras, tal como ocurre al hombre-lobo Rivero Puig.

Pero nos interesan más ahora las alusiones a otros discursos literarios o artísticos. Sin pretender agotar la multirreferencialidad del cuento, señalaremos dos de innegable atractivo.

1. La primera se sitúa en la base del argumento y actúa como elemento configurador del ambiente geográfico del relato. Adolfo Bioy Casares ha hablado con frecuencia de la máxima de austeridad que impone a toda su producción, y que se traduce en la supresión de todo dato superfluo. Esta ley económica es la que funciona en «Confidencias de un lobo», de modo que con exiguas menciones al «crepuscular Arco de Triunfo», a la iglesia de la Magdalena, a románticas placitas y al Bois de

\footnotetext{
${ }^{2}$ Adolfo Bioy Casares, La invención de Morel. El gran serafin (Madrid: Cátedra, 1982), p. 223.

${ }^{3}$ Bioy Casares, p. 231.
} 
Boulogne, se configura una reconocible estampa del París bohemio y galante. Los cuatro amigos sienten que su necesidad de aventuras sentimentales se acrecienta en París, «donde la realidad toda se volcaba en una frenética zarabanda -tal les pareció a ellos- en homenaje a los triunfos del amon». Mimí, la «francesita», contribuye al tópico nacional cuando Rivero Puig la reconoce «tan bonitilla como fresca, el auténtico artículo de París»5.

Bioy Casares juega pues con una imagen de la capital francesa que desde finales del siglo XIX se difunde a través de la literatura, la pintura y las agencias de viajes. También a través de la música, y pensamos ahora en la que puede ser referencia directa del relato: la ópera La bohème de Puccini.

En esta célebre creación musical los protagonistas son también cuatro hombres, un pintor, un músico, un filósofo y un poeta. Representantes de la más genuina bohemia artística parisina, pasan sus días entre chispeantes diálogos y complicaciones amorosas; pero no sólo este aspecto los iguala a los modernos héroes de Bioy, sino que la angustiosa miseria de los bohemios de Puccini se corresponde con la inseguridad financiera que atormenta a los turistas en las primeras páginas de «Confidencias de un lobo». «Fuera del país.... se va la plata», se admite en cierto momento, pero «aunque ahora parezca increíble, ya verán que los recuerdos del viaje resultarán impagables», los tranquiliza el touroperador. Idéntica filosofía despreocupada es la que hacía heroicos a los artistas del París bohemio de Puccini.

Tal como del cuarteto de Bioy se destaca la figura soñadora de Rivero Puig, Puccini había singularizado en su ópera a Rodolfo, poeta entregado al sobrio ejercicio literario que encuentra también una amada llamada Mimí. Este es el punto en que resulta más clara la referencia entre ambos discursos artísticos, quizá. Rodolfo, espíritu superior, admite que «per sogni e per chimere/e per castelli in aria,/l'anima ho milionaria», y esa propensión a la quimera y a la ensoñación, a los castillos en el aire, le hace confiar en Mimí -otro personaje un tanto ambiguo, pues su nombre auténtico resulta ser Lucía-. Esta Mimí, como la de Bioy Casares, es hermosa y dulce pero algo casquivana, provocando el continuo mal de celos de Rodolfo. El poeta conoce el avance de la tuberculosis en el pecho de su amada y decide renunciar a ella para que pueda hallar en otro acompañante más adinerado las atenciones que requiere, de modo que la separación entre los amantes -antes de la escena final, en el lecho de muerte de Mimíno incide con acritud excesiva en la infidelidad de esta nueva Manon. Pero es interesante acudir a la fuente novelesca de la ópera, la novela-ensayo de Henri Murguer La bohemia, para reencontrar a una Mimí dotada de todos los atributos de la joven prostituta que finge con maestría amores sinceros. Rodolfo se cuestiona en la novela su fracaso con palabras que bien pudo aplicarse Rivero Puig: «¿Qué será mejor, dejarse engañar siempre por haber creído, o no creer nunca por temor de ser engañado?»

Estas referencias intertextuales nos interesan, más que por su valor explicativo, porque nos ayudan a entender los mecanismos técnicos del narrador argentino tal

\footnotetext{
${ }^{4}$ Bioy Casares, p. 226.

${ }^{5}$ Bioy Casares, p. 231.

${ }^{6}$ Henri Murguer, La bohemia (Madrid: Pueyo, 1969), p. 164.
} 
como los anunciábamos en un principio: si los amores desgraciados de Puccini y Murguer ponían en evidencia la imposibilidad del ideal utópico de la vida bohemia, Bioy Casares va mucho más lejos al degradar a Mimí hasta convertirla en una impostora que reproduce el viejo mito de la «cocotte» parisina, y al poeta soñador en un mediocre turista argentino arrastrado por los tópicos a vivir una humillante aventura erótica en un París definitivamente anacrónico e irrecuperable. Estamos ante lo que Suzanne Levine ha llamado efecto de «anti-utopía» en los textos de Bioy Casares?

2. En segundo lugar, el entramado intertextual descubre varias referencias a la figura mítica del licántropo. Rivero Puig se autodescribe en la primera página del relato como un «lobo solitario», y más adelante encuentra en este animal legendario una cabal imagen de sí mismo. No hay apenas más alusiones zoomórficas en el texto con excepción de la que por su importancia comentaremos más adelante. Sin embargo, el título que Bioy otorga al relato nos garantiza la consciente utilización de un esquema mítico-literario de gran peso en la cultura occidental.

A pesar de su popularización contemporánea gracias a producciones cinematográficas como El hombre-lobo (1941) o Frankenstein y el hombre-lobo (1943)-por citar sólo las más antiguas-, la figura del hombre-lobo o licántropo es anterior en más de mil años a la caracterización de Lon Chaney Jr. Basta recordar que su origen se sitúa en las ancestrales leyendas galas y germánicas, y que ya en la Biblia se recoge un curioso fenómeno licantrópico en Nabucodonosor, constructor de Babilonia. La tradición grecolatina nos ha legado el mito de Licaón, convertido por Zeus en lobo por haberle ofrecido en un banquete la carne de un niño, y nos ha hablado de ritos licantrópicos en que se devoraban las entrañas humanas de la víctima inmolada al dios.

La psicología contemporánea ha interpretado esta tradición como simbolización de la «irracionalidad latente en la parte inferior del hombre» ${ }^{8}$. Más interesante, aún a riesgo de extender excesivamente esta digresión, resulta atender a las conclusiones de la psiquiatría al respecto. Calmeil, especialista del siglo pasado, anotaba que la presión ejercida por tan larga tradición oral y escrita había conducido a algunas imaginaciones crédulas e impresionables a la insana perturbación de creerse metamorfoseados en lobo bajo los efectos de la luna llena. Los hubo que se limitaban a soñar con correrías por la nieve y depredaciones sangrientas; otros llegaron realmente a deambular por los bosques cubiertos de pieles de lobo tras presas animales o humanas.

La vasta cultura de Bioy Casares no podía ignorar estos datos a la hora de componer su relato, y nos preguntamos entonces qué sentido puede tener la insinuación de licantropía que desliza sobre su personaje. El lector que ha decidido entrar en el juego de evocaciones literarias que propone Bioy Casares en el título del relato y en la confesión inicial del protagonista se siente inmediatamente sorprendido ante la falta de agresividad de Rivero Puig. Muy lejos de la liberación de los instintos de que hablábamos hace unos instantes, el turista argentino se muestra reflexivo y prudente,

\footnotetext{
${ }^{7}$ Suzanne Levine, Guía de Bioy Casares (Madrid: Espiral Fundamentos, 1982).

${ }^{8}$ Juan Eduardo Cirlot, Diccionario de símbolos (Barcelona: Labor, 1982), p. 277.
} 
como cuando desaconseja a los amigos entablar relaciones con el personal femenino del hotel por temor a infringir los reglamentos de la hostelería.

Rivero Puig quiere ser enérgico y por ello camina rápidamente por las calles de París, aunque sin dirección alguna: «A toda costa había que evitar el cansancio pues fatalmente se lo tomaba por tristeza» ${ }^{9}$. Cuando siente frío mientras almuerza con Mimí en la terraza de un restaurante disimula con resuelto ademán, «no se diga que un criollo envidia el aguante de los extranjeros ${ }^{10}$. Al compararse con el lobo disecado se reconoce, como él, «carnicero», y más tarde confirma la definición: «¿Les doy el secreto? Atropellar a ojos cerrados. ¡En tierra extranjera el arrastre del criollo es irresistible! ${ }^{11}$.

Ante tal actitud del porteño arrogante y machista que Bioy Casares ha denunciado con frecuencia en su obra, el narrador interviene con una tercera alusión licantrópica que es definitiva para entender el sentido del relato. Rivero Puig, observando a Mimí y extrapolando sus actitudes al resto de las jóvenes modernas, concluye: «Desde luego vive hambrienta, a salto de mata, merodeando los hombres de cuya mayo recibe alimento... Pobres mujeres, tan esforzadas en su fragilidad, pensaba, sin reparar hasta qué punto, por lo ávidas, por lo implacabes y por lo feroces correspondían al símbolo que en divagación romántica había adoptado para sí» ${ }^{12}$. Es decir, paradójicamente, Mimí resulta ser la loba y Rivero la incauta presa.

Bioy Casares no es el primer autor que invierte tan decididamente el mito. Ya en la novela cervantina Persiles y Segismunda aparecían mujeres medio-lobas, mediobrujas, destacadas por su maldad. Pero nos atreveríamos a asegurar que el narrador argentino es en este caso deudor de un novelista más contemporáneo, Boris Vian. Entre los relatos del escritor francés sobresale sin duda el titulado «El lobo-hombre», compuesto en 1947 -veinte años antes de la publicación de El gran serafín-. Boris Vian llega a invertir tan radicalmente la figura legendaria que propone un caso de antropolicandría, es decir, la metamorfosis en hombre del simpático lobo Denis por efecto de la mordedura de un hombre-lobo.

La experiencia de Denis tiene varios puntos en común con la de Rivero Puig. Para empezar, se trata también de un personaje pacífico, sensato y civilizado con el que no cuadra excesivamente la condición de lobo solitario. Denis viaja igualmente a París, y allí su candidez topa con una hermosa seductora a quien confunde con una chica formal. La falacia se descubre cuando la joven aprovecha su reposo para sustraerle unos francos del bolsillo. Ante el desconcierto de Denis, ella reaccionará de forma opuesta a la Mimí de Bioy Casares cuando exclama que «no acostumbra a tirarse a los pasmados por el gusto de hacerlo» ${ }^{13}$.

\footnotetext{
${ }^{9}$ Bioy Casares, p. 230.

${ }^{10}$ Bioy Casares, p. 233.

${ }^{11}$ Bioy Casares, p. 240.

12 Bioy Casares, p. 232.

${ }^{13}$ Boris Vian, El lobo-hombre (Barcelona: Tusquets Editores, 1987), p. 20.
} 
A partir de este punto el relato de Boris Vian deriva hacia episodios ajenos al de Bioy. Sin embargo, creemos que su fondo argumentístico pudo estar presente en el narrador argentino. Es interesante además señalar cómo son comunes a ambos narradores varios aspectos técnicos, a pesar de que Bioy no cita en ningún momento al autor francés entre sus posibles modelos. Así, acostumbra Boris Vian a salpicar sus narraciones con citas literarias irónicas -que, de nuevo, despistan al lector antes que lo ayudan-, a entrelazar sin solución el registro literario con la frase coloquial, o a romper la distancia autor-lector con referencias al propio discurso, procedimientos todos afines a la narrativa de Bioy Casares.

Pero nos interesa encaminarnos ya hacia una conclusión válida. Si anteriormente descubríamos que la recreación paródica del ambiente decadentista parisino -a través de su máxima encarnación en las obras de Murguer y Puccini- servía al autor para invalidar la falsa utopía bohemia, la inversión irónica del mito de la licantropía -a través del posible referente ya invertido de Boris Vian- es utilizado para una nueva revisión crítica, la del argentino que revela fuera de su tierra su triste insignificancia. La aguda ironía de Bioy Casares no perdona el falso idealismo europeo, pero tampoco el ridículo orgullo americano.

Suzanne Levine ha estudiado entramados semejantes en novelas como $\mathrm{La}$ invención de Morel y Plan de evasión. En efecto, Bioy afirma con frecuencia que la realidad literaria contrae a los ojos del autor tanto o más significado que la del universo natural. La fuente de inspiración del texto es un texto previo -a veces, varios-, y la actividad creativa es a la par escritura y relectura. Finalmente, el sentido de la relectura en el narrador argentino es con frecuencia, lo acabamos de comprobar, el que impone la distancia irónica y subversiva. Por todo ello, es lícito hablar de intertextualidad de diferencias, intertextualidad con finalidad crítica que vertebra también nuestro relato. Como las profecías antiguas auguraban, a menudo los lobos son devorados por los corderos. 